\title{
The Apolipoprotein E $\epsilon 4$ Allele Is Associated with Blunting of Ketamine-Induced Psychosis in Schizophrenia A Preliminary Report
}

\author{
Anil K. Malhotra, M.D., Alan Breier, M.D., David Goldman, M.D.,
} Lisa Picken, B.A., and David Pickar, M.D.

Interindividual differences in the psychotomimetic response to the $\mathrm{N}$-methyl-d-aspartate receptor antagonist ketamine are commonly observed. The apolipoprotein $E$ (APOE) $\epsilon 4$ allele has been associated with reduced severity of positive psychotic symptoms in schizophrenia. In this study, we sought to determine if the APOE $\epsilon 4$ allele influences the psychotomimetic response to ketamine in schizophrenics. Eighteen patients genotyped at the APOE locus underwent a double-blind infusion of ketamine and of placebo.

Ketamine-induced alterations in the brief psychiatric rating scale factors were compared between schizophrenics with and without the APOE $\epsilon 4$ allele. APOE $\epsilon 4+$ schizophrenics displayed significantly reduced ketamineinduced psychosis, as compared to $\epsilon 4-$ patients. These preliminary data indicate that the psychotomimetic response to ketamine may be genetically influenced and may provide additional evidence that APOE may modify expression of the positive symptoms in schizophrenia.

[Neuropsychopharmacology 19:445-448, 1998]

Published by Elsevier Science Inc.
KEY WORDS: Ketamine; N-Methyl-d-aspartate; Psychosis; APOE; Genotype

The N-methyl-d-aspartate (NMDA) receptor antagonist, ketamine, has been used to pharmacologically probe the glutamatergic system (Krystal et al. 1994; Lahti et al. 1995; Malhotra et al. 1996a; Breier et al. 1997). In healthy subjects, subanesthetic doses of ketamine produce thought disorder, blunted affect, and cognitive deficits that resemble aspects of schizophre-

From the Experimental Therapeutics Branch (AKM, AB, LP, DP), National Institute of Mental Health, National Institutes of Health, Bethesda, MD, USA; and the Laboratory of Neurogenetics (DG), National Institute of Alcohol Abuse and Alcoholism, National Institutes of Health, Bethesda, MD, USA

Address correspondence to: Anil K. Malhotra, M.D., Hillside Hospital, Research, 75-59 263rd St, Glen Oaks, NY 11004.

Received October 13, 1997; accepted March 9, 1998. nia (Krystal et al. 1994; Malhotra et al. 1996a). In schizophrenics, ketamine can exacerbate psychosis and cognitive impairment (Lahti et al. 1995; Malhotra et al. 1997a). A notable feature of the behavioral response to ketamine is the marked interindividual variation in severity of ketamine-induced psychosis. A subgroup of schizophrenics experience profound exacerbation of psychotic symptoms with increased hallucinations, conceptual disorganization, and paranoia during ketamine administration; whereas, other patients note little or no change (Malhotra et al. 1997a; Malhotra et al. 1997b). The mechanism for the variation in the psychotomimetic response to ketamine remains to be established.

Recent studies have attempted to link interindividual differences in behavior to genetic variation (Ebstein et al. 1996; Benjamin et al. 1996; Malhotra et al. 1996b; Lesch et al. 1996). Apolipoprotein E (APOE) is a lipidtransport-associated protein with three common alleles, 
$\epsilon 2, \epsilon 3$, and $\epsilon 4$ (Strittmatter and Roses 1995). In 52 antipsychotic drug (APD)-free schizophrenics, we have observed an association between APOE genotype and severity of positive psychotic symptoms (Pickar et al. 1997). Patients with the APOE $\epsilon 4$ allele exhibited $50 \%$ lower psychosis ratings than patients without the $\epsilon 4$ allele. To investigate to role of APOE $\epsilon 4$ in the expression of psychotic symptoms, we genotyped a group of schizophrenics who underwent double-blind, placebocontrolled ketamine infusions to test the hypothesis that APOE $\epsilon 4$ is associated with blunting of ketamineinduced psychosis.

\section{METHODS}

Eighteen patients (age $=34.7(2.3)$ yrs, 13M, 5F) with schizophrenia or schizo-affective disorder as determined with the Structured Clinical Interview for DSMIII-R (Spitzer et al. 1990) participated after giving written informed consent to a NIMH IRB-approved protocol. Subjects were in good physical health and free from drug and alcohol abuse for at least 6 months. Three patients were fluphenazine (FLU)-treated, four were clozapine (CLZ)-treated, and 11 were APD-free. APOE genotype frequencies were $\epsilon 3 / \epsilon 3: 56 \%, \epsilon 2 / \epsilon 3: 6 \%, \epsilon 3 / \epsilon 4$ : $33 \%, \epsilon 4 / \epsilon 4: 6 \%$. Because this study group contained only one $\epsilon 4 / \epsilon 4$ subject, the $\epsilon 3 / \epsilon 4$ and $\epsilon 4 / \epsilon 4$ subjects were combined as the $\epsilon 4+$ study group. The $\epsilon 3 / \epsilon 3$ and $\epsilon 2 / \epsilon 3$ genotypes were combined as the $\epsilon 4$ - group.

Each subject underwent an infusion of ketamine and of placebo. Order was randomized, and infusions were separated by at least 1 day. On each study day, intravenous lines were inserted $60 \mathrm{~min}$ before administration of a $0.12 \mathrm{mg} / \mathrm{kg}$ bolus of ketamine or placebo followed by a $0.65 \mathrm{mg} / \mathrm{kg}$ infusion of ketamine or placebo over 1 h. Symptoms were assessed with the 18-item Brief Psychiatric Rating Scale (BPRS) (Overall and Gorham 1962) $30 \mathrm{~min}$ before $(-30)$ infusion and at $+10,+35,+55,+90$ and +120 min of each infusion by a rater blind to drug and to genotype. APOE genotyping was performed using the method of Hixson and Vernier (1990).

The BPRS factors for psychosis (items for conceptual disorganization, suspiciousness, hallucinations, and unusual thought content), withdrawal-retardation (emotional withdrawal, motor retardation, and blunted affect) and anxiety-depression (anxiety, guilt feelings, and depressive mood) were analyzed. Analysis of variance (ANOVA) was conducted to examine ketamine effects in the 18 subjects. To examine differences in ketamine response between $\epsilon 4+$ and $\epsilon 4-$ subjects, delta scores were calculated between ketamine and placebo BPRS scores at baseline to peak drug effect $(+55 \mathrm{~min})$ $\left[\left(\mathrm{BPRS}_{\text {Ket }(+55)}-\mathrm{BPRS}_{\mathrm{Ket}(-30)}\right)-\left(\mathrm{BPRS}_{\mathrm{Pbo}(+55)}-\mathrm{BPRS}_{\mathrm{Pbo}}\right.\right.$ $(-30))]$ for each subject and compared with $t$-tests (twotailed). All data are reported \pm SEM.

\section{RESULTS}

Ketamine produced significant increases in BPRS ratings of psychosis and withdrawal-retardation but did not significantly alter anxiety-depression ratings in the 18 schizophrenics (Table 1 ).

Seven subjects were APOE $\epsilon 4+; 11$ were $\epsilon 4-$. $€ 4+$ patients experienced significantly less ketamine-induced increases in psychosis ratings than $\epsilon 4-$ patients $(t=2.70$, $\mathrm{df}=16, p=.02$ ) (Figure 1). Individual BPRS psychosis delta scores for the $11 \in 4-$ subjects were $3,3,3,4,5,5,5$, $7,8,9,12$. Individual BPRS psychosis delta scores for the $7 \in 4+$ subjects were 1, 2, 2, 3, 3, 4, 4. Exploratory examination of the individual items comprising the psychosis factor revealed the greatest difference between $\epsilon 4-$ and the $\epsilon 4+$ groups on the item for unusual thought content $(\epsilon 4-=1.73, \epsilon 4+=0.71, p=.06)$. No significant differences in ketamine response were observed for withdrawal-retardation $(t=0.64, \mathrm{df}=16$, $p=.53)$ or anxiety-depression $(t=0.38, \mathrm{df}=16, p=.71)$ between $\epsilon 4+$ and $\epsilon 4-$ patients.

Table 1. Ketamine Effects on BPRS Scores ${ }^{a}$ in Schizophrenic Patients $(n=18)$

\begin{tabular}{|c|c|c|c|c|c|c|c|c|}
\hline & -30 & +10 & +35 & +55 & +90 & +120 & $\mathrm{~F}(\mathrm{df}=5,85)^{b}$ & $p^{b}$ \\
\hline \multicolumn{9}{|l|}{ Psychosis } \\
\hline Ketamine & $8.8(0.73)$ & $12.3(0.77)^{c, d}$ & $13.1(0.94)^{c, d}$ & $12.9(0.97)^{c, d}$ & $9.7(0.80)$ & $8.8(0.78)$ & \multirow{2}{*}{28.4} & \multirow{2}{*}{$<.01$} \\
\hline Placebo & $9.0(0.80)$ & $8.8(0.71)$ & $8.6(0.64)$ & $8.6(0.66)$ & $8.8(0.73)$ & $8.7(0.75)$ & & \\
\hline \multicolumn{9}{|c|}{ Withdrawal-retardation } \\
\hline Ketamine & $7.0(0.59)$ & $8.2(0.73)$ & $9.0(0.97)^{d}$ & $8.7(0.92)$ & $7.0(0.59)$ & $7.0(0.49)$ & \multirow{2}{*}{3.2} & \multirow{2}{*}{.01} \\
\hline Placebo & $7.7(0.64)$ & $7.7(0.64)$ & $7.6(0.68)$ & $7.5(0.66)$ & $7.4(0.73)$ & $7.7(0.68)$ & & \\
\hline \multicolumn{9}{|c|}{ Anxiety-depression } \\
\hline Ketamine & $4.9(0.47)$ & $5.3(0.49)$ & $5.6(0.57)$ & $4.9(0.49)$ & $4.6(0.45)$ & $4.8(0.45)$ & \multirow{2}{*}{1.7} & \multirow[b]{2}{*}{.1} \\
\hline Placebo & $4.9(0.52)$ & $4.5(0.49)$ & $4.3(0.49)$ & $4.3(0.47)$ & $4.3(0.42)$ & $4.3(0.40)$ & & \\
\hline
\end{tabular}

$a=$ Mean $(\mathrm{SEM})$

${ }^{b}=$ ANOVA drug $\times$ time

${ }^{c}=p<.05$ vs. placebo

${ }^{d}=p<.05$ vs. baseline $(-30)$ 


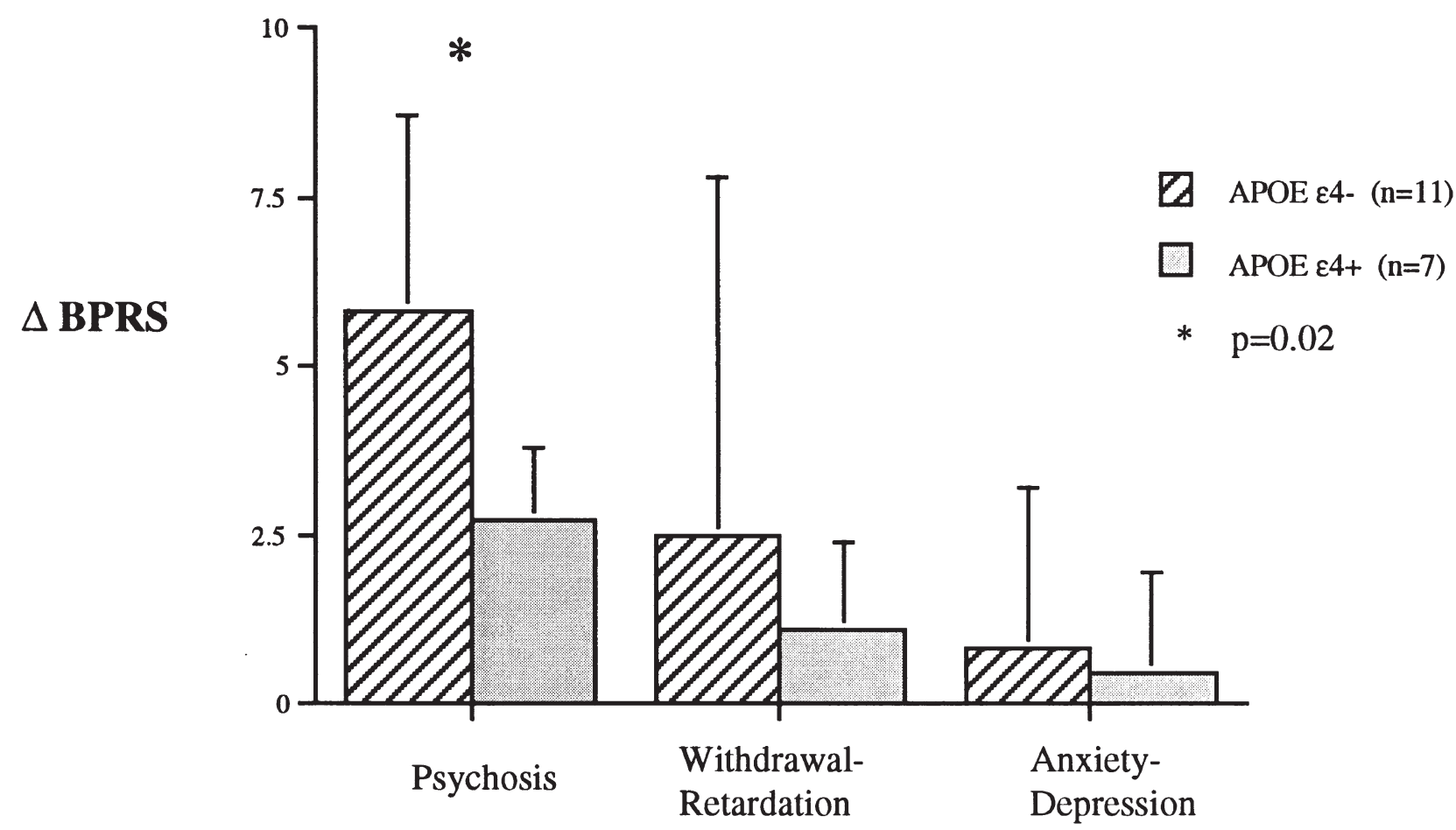

\section{BPRS factor}

Figure 1. Ketamine-induced effects on BPRS factor ratings in APOE $\epsilon 4+$ and APOE $\epsilon 4-$ schizophrenic patients. Delta scores were calculated between ketamine and placebo BPRS scores at baseline-to-peak drug effect $\left(\mathrm{BPRS}_{\mathrm{ket}(+55)}-\mathrm{BPRS}_{\mathrm{ket}(-30)}\right)-$ $\left(\mathrm{BPRS}_{\mathrm{pbo}(+55)}-\mathrm{BPRS}_{\mathrm{pbo}(-30)}\right)$. APOE $\epsilon 4+$ patients had significantly less ketamine-induced psychosis than APOE $\epsilon 4-$ patients. There were no significant differences in anxiety-depression $(p=.53)$ or withdrawal-retardation $(p=.71)$. All data are shown + SD.

There were no significant differences in gender $(\epsilon 4+=$ $4 \mathrm{M}, 3 \mathrm{~F}, \epsilon 4-=9 \mathrm{M}, 2 \mathrm{~F}$, Fishers' exact $p=.27)$, ethnicity $(\epsilon 4+=6$ whites, 1 black, $\epsilon 4-=9$ whites, 1 black, 1 Asian, Fishers' exact $p=.67$ ), age $\epsilon 4+=33.6$ (4.4) yrs, $\epsilon 4-=34.5$ (3.0) yrs, $t=0.17, \mathrm{df}=16, p=.86)$, ketamine dose $(\epsilon 4+=53.7$ (4.3) $\mathrm{mg}, \epsilon 4-=60.0(2.0) \mathrm{mg}, t=1.51$, $\mathrm{df}=16, p=.15)$ or baseline BPRS psychosis factor ratings $(\epsilon 4+7.6(0.8), \epsilon 4-=9.5(1.1), t=1.34, \mathrm{df}=16, p=$ $.20)$ between groups. One $\epsilon 4+$ subject was FLU-treated $(25 \mathrm{mg} /$ day); six were APD-free. Two $\epsilon 4-$ subjects were FLU-treated ( $20 \mathrm{mg} /$ day), 4 were CLZ-treated (281 [53.5] mg/day), and five were APD free.

\section{CONCLUSIONS}

The psychotomimetic effects of ketamine were reduced in schizophrenics with the APOE $\epsilon 4$ allele, as compared to $\epsilon 4-$ patients. No differences were identified in ketamine's effects on negative symptoms or anxietydepression by APOE genotype. Consistent with our previous reports (Malhotra et al. 1997a,b), in the schizo- phrenic group as a whole, ketamine exacerbated positive and negative symptoms but not anxiety-depression ratings. However, considerable overlap exists between this study group and our previous ketamine study groups.

These data are consistent with our observation that APOE $\epsilon 4+$ schizophrenics experience significantly less positive symptoms than $\epsilon 4-$ patients while APD-free (Pickar et al. 1997). The association between $\epsilon 4$ and muted positive symptoms, therefore, seems to be independent of whether symptoms are related to APD-free status or are pharmacologically induced with an NMDA antagonist. We speculate that APOE's role in neuronal degeneration or antioxidant activity (Miyata and Smith 1996) may disrupt a putative neural circuit involved in the pathophysiology of psychotic symptoms. Independent replication of these data and examination of APOE in other syndromes with psychosis are needed to confirm this. Moreover, larger study groups would allow for more precise evaluation of the potential roles of ethnic stratification, differential metabolism of ketamine, and the age-dependent effects of APOE on CNS function in this preliminary result. 
Previous pharmacogenetic studies have reported associations between genetic variation and drug response. Perhaps the best known association is between an aldehyde dehydrogenase polymorphism and alcohol response (Harada et al. 1985). Our data suggest that interindividual variations in the psychotomimetic response to NMDA antagonists also may be genetically influenced. Examination of APOE in drug abusers-in particular, phencyclidine abusers-would be of interest, because individuals with enhanced drug responsivity may be predisposed to repeated use of psychotomimetic agents.

An important consideration in the interpretation of our data is the role of concomitant APD treatment. However, six of the seven $\epsilon 4+$ subjects (reduced ketamine response) were APD-free during ketamine infusion. The $\epsilon 4-$ group (greater ketamine response) contained more APD-treated subjects than the $\epsilon 4+$ group. In fact, the $\in 4-$ group contained four subjects on CLZ which, unlike typical neuroleptics (Lahti et al. 1995), has been reported to diminish the psychotomimetic response to ketamine in a study of 10 patients (Malhotra et al. 1997b). Therefore, based upon APD status alone, $\epsilon 4-$ subjects would be predicted to experience decreased ketamine response, not the enhanced response observed here. However, replication of these data in APD-free patients would be of interest.

In conclusion, we report an association between APOE genotype and the psychotomimetic response to ketamine. These data provide preliminary evidence for a role of APOE in the interindividual variation in psychotomimetic drug response and may suggest that the APOE $\epsilon 4$ allele modifies the expression of positive symptoms in schizophrenia.

\section{REFERENCES}

Benjamin J, Greenberg B, Murphy DL, Lin L, Patterson C, Hamer DH (1996): Population and familial association between the $\mathrm{D}_{4}$ dopamine receptor gene and measures of novelty seeking. Nature Genet 12:81-84

Breier A, Malhotra AK, Pinals DA, Weisenfeld NI, Pickar D (1997): Association of ketamine-induced psychosis with focal activation of the prefrontal cortex in healthy volunteers. Am J Psychiat 154:805-811

Ebstein RP, Novick O, Umansky R, Priel B, Osher Y, Blaine D, Bennett E, Nemanov L, Katz M, Melmaker R (1996): Dopamine $\mathrm{D}_{4}$ receptor (D4DR) exon III polymorphism associated with human personality trait of novelty-seeking. Nature Genet 12:78-80
Harada S, Agarwal DP, Goedde HW (1985): Aldehyde dehydrogenase polymorphism and alcohol metabolism in alcoholics. Alcohol 2:391-392

Hixson JE, Vernier DT (1990): Restriction isotyping of human apolipoprotein $\mathrm{E}$ by gene amplification and cleavage with HhaI. J Lipid Res 31:545-548

Krystal JH, Karper LP, Seibyl JP, Freeman GK, Delaney R, Bremmer JD, Heninger GR, Bowers MB Jr, Charney DS (1994): Subanesthetic effects of noncompetitive NMDA antagonist, ketamine, in humans: Psychomimetic, perceptual, cognitive, and neuroendocrine responses. Arch Gen Psychiat 51:199-214

Lahti AC, Koffel B, LaPorte D, Tamminga CA (1995): Subanesthetic doses of ketamine stimulate psychosis in schizophrenia. Neuropsychopharmacology 13:9-19

Lesch KP, Bengel D, Heils A, Sabol SZ, Greenberg BD, Petri S, Benjamin J, Müller CR, Hamer DH, Murphy DL (1996): Association of anxiety-related traits with a polymorphism in the serotonin transporter gene regulatory region. Science 274:1527-1531

Malhotra AK, Pinals DA, Adler CM, Elman I, Clifton A, Pickar D, Breier A (1997a): Ketamine-induced exacerbation of psychotic symptoms and cognitive impairment in neuroleptic-free schizophrenics. Neuropsychopharmacology 17:141-150

Malhotra AK, Adler CM, Kennison SD, Elman I, Pickar D, Breier A (1997b): Clozapine blunts N-methyl-D-aspartate antagonist-induced psychosis: A study with ketamine. Biol Psychiat 42:664-668

Malhotra AK, Pinals DA, Weingartner H, Sirocco K, Missar CD, Pickar D, Breier A (1996a): NMDA receptor function and human cognition: The effects of ketamine in healthy volunteers. Neuropsychopharmacology 14:301307

Malhotra AK, Virkkunen M, Rooney W, Eggert M, Linnoila M, Goldman D (1996b): The association between the dopamine $\mathrm{D}_{4}$ receptor (D4DR) 16 amino acid repeat polymorphism and novelty seeking. Mol Psychiat 1:388-391

Miyata M, Smith JD (1996): Apolipoprotein E allele-specific antioxidant activity and effects on cytotoxicity by oxidative insults and $\beta$-amyloid peptides. Nat Genet 14:55-61

Overall JE, Gorham DR (1962): The brief psychiatric rating scale. Psychol Rep 10:799-812

Pickar D, Malhotra AK, Rooney W, Breier A, Goldman D (1997): Apolipoprotein E $\epsilon 4$ allele and clinical phenotype in schizophrenia. Lancet 350:930-931

Spitzer RL, Williams JBW, Gibbon M, First MB (1990): Structured Clinical Interview for DSM-III-R-Patient Version 1.0 (SCID-P). Washington, DC, American Psychiatric Press

Strittmatter WJ, Roses AD (1995): Apolipoprotein E and Alzheimer disease. Proc Natl Acad Sci USA 92:47254727 